\title{
THE CURRENT FRAMEWORK FOR TOBACCO CONTROL
}

\section{Catriona O'Neill}

Tobacco and Health Unit,

NSW Department of Health

Smoking causes one-third of all cancers and accounts for around 6,600 cancer-related deaths in Australia each year. ${ }^{1}$ This article describes the draft Tobacco Action Plan 2001-2004, produced by the NSW Department of Health, which aims to improve people's health by eliminating or reducing their exposure to tobacco.

\section{TOBACCO AND CANCER}

Cancers with smoking as a major cause include:

- lung cancer

- oesophageal cancer

- oropharyngeal cancer

- cervical cancer. $^{2}$

Lung cancer remains the leading cause of death due to cancer in Australian men. Men have always had a higher prevalence of smoking than women, although the rates of smoking between men and women are converging. Of cases of lung cancer, 84 per cent in men and 77 per cent in women can be attributed to smoking. Duration of smoking, in particular the role of smoking early in life, is the most significant factor known to influence the risk of developing lung cancer. Most smokers take up the habit while still teenagers. ${ }^{2}$

\section{THE TOBACCO ACTION PLAN 2001-2004}

The draft Tobacco Action Plan 2001-2004 has been developed by the NSW Department of Health in collaboration with key stakeholders. It represents an ongoing commitment to tobacco control in NSW and provides a framework for improving the health of the people of NSW by eliminating or reducing their exposure to tobacco in all its forms. The plan accords with the National Tobacco Strategy 1999-2003, and builds upon the previous NSW Department of Health tobacco strategy, the Tobacco and Health Strategy 1995-1999.

In line with the National Tobacco Strategy, the plan focuses on the following six areas:

- community awareness and education

- smoking cessation

- availability and supply of tobacco products

- marketing and promotion of tobacco

- tobacco product regulation

- exposure to environmental tobacco smoke.

The major priority within the plan is reducing the prevalence of smoking. Preventing uptake of smoking and improving the availability and accessibility of cessation services for smokers who wish to quit will result in fewer users of tobacco products in the long term and, consequently, reduce morbidity and premature mortality in NSW. In addition to this priority for the whole population, a number of target groups are also prioritised within the plan:

- children and young people;

- Aboriginal and Torres Strait Islander populations;

- non-English speaking background communities with high smoking rates;

- people with a mental illness.

\section{ADDRESSING SMOKING PREVALENCE: PUBLIC EDUCATION AND CESSATION SERVICES}

The National Tobacco Campaign Every cigarette is doing you damage has been the most successful antismoking campaign aimed at current smokers. Findings have included a statistically significant reduction of about 1.5 per cent in the estimated adult prevalence of smoking in Australia. ${ }^{3}$ The NSW QUIT Campaign supports the National Tobacco Campaign and other national and international events such as World No Tobacco Day (WNTD) and the New Year Campaign.

Activities in NSW for the WNTD 2000 included:

- commercials in the electronic media;

- advertisements in the print media;

- development of promotional resources;

- health promotions on the NSW Department of Health's Web site;

- a campaign targeting smokers from non-English speaking backgrounds;

- area health service grants for local promotional activities.

In 2000, the NSW Department of Health provided sponsorship for:

- the Rock Eisteddfod Challenge (REC), a performing arts competition for secondary schools;

- the National Rugby League (NRL) Smoke Free Final Series. This was complemented by a tobacco prevention program in schools, which included a pilot program run in three areas of NSW this year as part of the NRL Junior Development Program.

Cessation services offered in NSW include a 24-hour Quitline service through which smokers wishing to cease smoking can order a Quit kit and/or speak to a counsellor. The area health services also provide counselling and some also run quit groups when there is a demand.

The NSW Department of Health supports easier access by smokers to nicotine replacement therapy (NRT). While there is no move to make such therapies available through the Pharmaceutical Benefits Scheme (PBS), a number of 
hospitals in the state provide NRT free of charge to inpatients.

\section{AVAILABILITY AND MARKETING OFTOBACCO}

NSW is a recognised leader in restricting the sale of tobacco to people under the age of 18. The Public Health Act 1991 was amended in 1996 to incorporate a proof of age requirement, and this amendment was strengthened by the implementation of routine compliance monitoring of tobacco retailers. Compliance monitoring is conducted with the assistance of underage volunteers who, under the supervision of health staff, attempt to buy cigarettes. Stores at which these underage volunteers are able to purchase cigarettes are given a warning notice in the first instance, and if they are again found selling tobacco to minors prosecution will usually follow. Around 125 successful prosecutions of retailers selling tobacco to minors have been recorded in NSW. The proportion of stores not selling to the volunteers, with results pooled from all area health services, provides a measure of the NSW compliance rate. In 1998-1999, NSW achieved a state average compliance rate of 84 per cent, which decreased slightly to 80 per cent in 1999-2000.

NSW has also strengthened its tobacco advertising laws, and the enforcement of these laws commenced in January 2000. Tobacco advertising is not permitted in NSW, and there are restrictions on the way tobacco can be displayed for sale. This is aimed at reducing the visibility of tobacco products in the community, which is particularly important in preventing the uptake of smoking among young people.

\section{SMOKING IN PUBLIC PLACES}

In NSW, the Smoke Free Environment Act 2000 came into effect on 6 September 2000. The Act:

- bans smoking in enclosed public places including shopping centres, restaurants, cafes, schools and colleges;

- provides an exemption from this ban in hotels, nightclubs, registered clubs, casino bar and gaming areas, and licensed reception areas in restaurants (smoking bans will extend to dining areas of hotels and clubs and licensed reception areas in restaurants from 6 September 2001);

- makes it an offence to smoke in an enclosed public place;

- requires the proprietor of a premises to direct patrons to stop smoking and, if the patrons continue to smoke, to leave the premises;

- includes the smoking of herbal cigarettes.

The Department of Health has conducted the first phase of a public education campaign to advise the general public and proprietors of the requirements of the legislation; this is to be followed up with further education and information.

The 1999 Smoke Free Workplace Policy was developed in consultation with area health services, health unions and WorkCover NSW with the goal to prohibit smoking throughout all area health service buildings; and in vehicles and property controlled by NSW Health by September 2002. The policy will provide employees and the public with a smoke free environment, increase cessation opportunities, set a healthy example to the community, and provide a best practice model for organisations wishing to go smoke free.

\section{PROTECTING CHILDREN FROM ENVIRONMENTALTOBACCO SMOKE}

A team of non-government organisations comprised of the National Heart Foundation of Australia (NSW Division), the Cancer Council of NSW, the Sudden Infant Death Association, and the Asthma Foundation of NSW have been awarded a grant by the NSW Department of Health to identify and examine research that underpins evidence-based interventions to reduce the exposure of children to environmental tobacco smoke.

\section{OLYMPIC AND PARALYMPIC NON SMOKING POLICY}

The Sydney Organising Committee for the Olympic Games (SOCOG) adopted a total indoor non-smoking policy. Smoking was not permitted in spectator areas inside Olympic or Paralympic venues; however, venues had designated outdoor smoking areas.

\section{THE FUTURE-IMPROVING PRODUCT REGULATION}

Tobacco, which contains nicotine, is highly addictive. However, unlike alcohol and other drugs, the sale of tobacco is subject to few restrictions, and the content of cigarettes is largely dependent on decisions of the manufacturers. There is great room for improvement in the regulation of tobacco products and in the provision of information to consumers and the general public about the constituents of tobacco products and tobacco smoke.

The draft Tobacco Action Plan 2001-2004 has identified improving tobacco product regulation as one of its six focus areas. The major strategy for the next five years in this regard is to develop, in collaboration with the Federal Government, a framework for the regulation of tobacco and nicotine products that may include:

- disclosure of contents, ingredients, nicotine levels, additives and poisons found in tobacco and tobacco smoke; 
- labelling health warnings on packages;

- taxation;

- the illicit tobacco trade;

- regulation of contents, ingredients, nicotine levels, additives and poisons found in tobacco.

\section{WORKING AS ATEAM}

In addition to the NSW Department of Health, there are many other stakeholders within NSW who are actively involved in the implementation of the draft Tobacco Action Plan 2001-2004. These include other government departments and non-government organisations such as the Cancer Council of NSW, the National Heart Foundation of Australia (NSW Division), and anti-smoking groups. The Tobacco Control Network was established in 2000 under the draft Tobacco Action Plan 2001-2004, with the aim of bringing together a large group of people who work on tobacco control to share information and ideas and to work collaboratively on projects aimed at reducing tobacco related harm.

The Tobacco Legislation Compliance (TLC) group, also formed as part of the plan, examines issues relating to the implementation of legislation and related programs such as the sales to minors program, enforcement of advertising laws and the introduction of smoke free public places legislation.

For further information on any of the above initiatives contact the Tobacco and Health Unit, NSW Department of Health, 73 Miller Street, North Sydney, NSW 2060; telephone: (02) 9391 9268; facsimile: (02) 9391 9579; or email: coneil@doh.health.nsw.gov.au.

\section{REFERENCES}

1. English DR, Holman CDJ, Milne MG et al. The quantification of drug caused morbidity and mortality in Australia. Canberra: Commonwealth Department of Human Services and Health, 1995.

2. Winstanley M, Woodward S and Walker N. Tobacco in Australia: Facts and Issues. Melbourne: Quit Victoria, 1995.

3. Commonwealth of Australia. Australia's National Tobacco Campaign Evaluation Report: Volume One Every cigarette is doing you damage. Canberra: Commonwealth Dept of Health and Aged Care, 1999. w

\section{ADVOCACY FOR TOBACCO CONTROL}

\section{Andrew Penman}

Chief Executive Officer

NSW Cancer Council

Although Australia is regarded as an example of best practice in tobacco control, the failure to achieve substantial reductions in smoking prevalence throughout the 1990s has been a source of frustration to its exponents. Not that the tobacco industry has had it all its own way:

- relatively constant prevalence belies significant drops in aggregate cigarette consumption;

- off-pack cigarette advertising has been virtually abolished;

- greater control is being exercised over sales to minors;

- nicotine replacement therapy can now be publicly promoted and is available over-the-counter;

- we have entered the new millennium with most public places now smoke free, and there is a very real commitment on the part of many governments to finishing this particular job.

But in some respects, it is striking how effectively the tobacco industry has turned political opinion on issues of central importance to it. The Corporate Affairs Plan of October 1992 for Philip Morris (Australia) Limited proposed to divert the Ministerial Council on Drug
Strategy from its 'misplaced' priority on tobacco towards illicit drugs. ${ }^{1}$ Anti-smoking campaigns were to be focused on youth, with the industry preferably taking a leading role according to this plan. This agenda was to be supported with 'enhanced' political connectivity, alliances with other industry groups, and the representation of Philip Morris as 'Philip Morris companies', not 'Philip Morris, the tobacco company'. Doubtless, enhanced connectivity would have carried a powerful message about the contribution of tobacco to the Australian economy.

In these circumstances, the interest of public health groups in developing new approaches to supplement the established portfolio of smoking abatement measures is understandable. Of these, litigation and regulation have been the most promoted. This article reviews the current role of litigation and regulation in tobacco control, and suggests other measures that can be taken to reduce tobacco smoking.

\section{LITIGATION}

The 11th World Conference on Tobacco or Health (WCTOH) was recently held in Chicago in the afterglow of the award of punitive damages in the case of Engle versus Reynolds Tobacco Company. So it is scarcely surprising that litigation ranked high on the conference 